\title{
Lacan e o feminismo francês: a história de uma (não) relação
}

\author{
Rafael Kalaf Cossi $\mathbb{1}^{*}$ \\ Universidade de São Paulo, Instituto de Psicologia. São Paulo, SP, Brasil
}

\begin{abstract}
Resumo: Este trabalho apresenta as teorias empreendidas pelas feministas francesas dos anos 1970, notadamente a respeito do uso e da interpretação que fizeram da psicanálise lacaniana, assim como o que consideramos ter sido a postura epistemológica que Lacan adota nesse momento. Fortemente marcadas por Derrida e o pósestruturalismo, Irigaray e Cixous tecem suas críticas ao arsenal teórico psicanalítico supostamente condizente com o modelo patriarcal, ao passo que concebem um tipo de escrita subversiva com aspirações políticas. Também nesse intuito, Montrelay e Kristeva pretendem oferecer uma sustentação teórica consistente com o movimento. Já Wittig, marcada pelo marxismo, lê os conceitos lacanianos como determinados pela mentalidade heterossexual enquanto regime político. Sustentamos que Lacan, atento ao entusiasmo feminista do período, opta por desenvolver sua teoria da sexuação e se dedica à formalização do aforismo "Não há relação sexual".
\end{abstract}

Palavras-chave: feminismo francês, psicanálise lacaniana, diferença dos sexos, não relação.

$\mathrm{O}$ feminismo pode ser didaticamente dividido em três ondas (Lago, 2010). A primeira é situada na virada do séculos XIX para o XX e no entreguerras, chamada "feminismo da igualdade" - reivindicava-se o direito ao voto, ao trabalho e à cidadania, ou seja, igualdade social e política com relação aos homens. A segunda onda, que foi até por volta dos anos 1980, é conhecida como "feminismo das diferenças" - além de dar força às lutas anteriores, mirava-se o mecanismo em jogo no sistema patriarcal que subjugava as mulheres; a crítica é contra a dominação masculina e as especificidades das mulheres tendem a ser exaltadas. A terceira onda do feminismo, iniciada a partir dos anos 1990, demanda a legitimação de novos modelos de identidade, práticas sexuais e relações de parentesco, ao questionar os processos de normatização de gênero.

Psicanálise e feminismo estão em diálogo desde seus primórdios e apresentam um percurso interimplicado: "emaranhados, não apenas constituíram um ao outro, como também nunca viveram separados" (Dimen citado por Roth, 2000, p. 189). Relação conflituosa, união paradoxal, "como gêmeos que estivessem, desde o começo, destinados ao amor e a rivalidade infinitos" (Bowlby citado por Brennan, 1997, p. 66).

No início do século $\mathrm{XX}$, prevalecia a concepção de que o baixo impacto da mulher no espaço público e sua módica participação nos processos de produção seriam decorrentes da função reprodutiva que lhe cabia, ou seja, seu aparato biológico justificaria sua menor importância sociopolítica - visão a ser combatida pelo grupo feminista. Neste sentido, a grande ênfase que a

* Endereço para correspondência: rkcossi@hotmail.com psicanálise dá à sexualidade feminina nos anos 1920 chama atenção.

Se, por um lado, Freud desenvolvia uma teoria que sustentava que o processo de constituição do sujeito como homem ou mulher é histórico ou cultural, na forma da trama edípica - ou seja, não temos um inalterável percurso biologicamente determinado; por outro, ele era acusado de ser mantenedor da subordinação da mulher a partir da alegação de que a diferença anatômica prescrevia a ela menor valor e inferioridade de condições quando comparada ao homem.

Surgem então, dentro do universo psicanalítico desse período, autores que se contrapunham às proposições freudianas, tais como Ernest Jones, Melanie Klein, Helene Deutsch e Karen Horney, que acabaram por contribuir com a articulação das posições feministas. Os principais pontos de divergência com Freud diziam respeito ao complexo de castração ser concebido como um processo único, válido para meninos e meninas; e ao fato de a libido também ser única, masculina assim como o falo, para tais autores, ser veiculado como um artifício teórico inerente ao pênis. O clitóris era reconhecido como uma versão feminina do pênis, libidinalmente desinvestido, à medida que a vagina entrava em cena; contudo, a menina sempre padecia da "inveja do pênis" - tal conjectura freudiana foi vigorosamente afrontada por Horney (1967/1993) e seu desenvolvimento da "inveja do útero".

Se a premissa é fálica, aqueles autores vão buscar explicar a mulher em si mesma, não por meio do modelo da organização da sexualidade masculina. Não à toa, enfatizam o período pré-edípico e a relação primordial mãe-filho, deslocando, assim, o pai do lugar privilegiado reservado a ele na teoria do Édipo. Freud (1931/2010) 
estava atento, comentando as teses de seus acusadores, sem abrir mão de suas prerrogativas: não existe uma fase fálica exclusiva das meninas, como queria Jones, e o falo tem papel central em ambos os sexos.

Lacan é deliberadamente discutido no meio feminista nos anos 1970 e, no trânsito da segunda para a terceira onda, esboça-se uma segmentação: de um lado, o que veio a ser denominado estudos de gênero norteamericanos, e de outro, o feminismo psicanalítico francês cada fração se concentrando em diferentes conjunturas lacanianas (Cossi, 2018). Enquanto o primeiro pretendia abalar o poder patriarcal e transformar a estrutura social a partir de reconfigurações das relações de parentesco e de trabalho, e da ideologia de gênero, o feminismo francês aspirava abalá-lo também pela linguagem e, aí sim, alterar o lugar da mulher no discurso.

Em 1975, a antropóloga Gayle Rubin inventa o sistema sexo/ gênero e inaugura uma vertente de trabalho no campo das ciências sociais. Lacan passa a ser discutido a partir das depurações simbólicas das estruturas elementares de parentesco: se em LeviStrauss é a troca de mulheres que funda a sociedade, sob a égide do tabu do incesto, o simbólico lacaniano subsidiaria tal circunstância, agora recorrendo ao falo enquanto significante e ao Édipo estrutural. A lei simbólica seria então uma marcada pela regência das relações de parentesco heterossexuais tidas como ideal interpretação prevalecente dos gender studies, como se detecta em Butler (1990/2003, 2004).

Já na comunidade francófona, as produções de Irigaray, Cixous, Montrelay, Kristeva e Wittig ganham destaque. Esse feminismo francês se mune principalmente do lacanismo que se prestou ao estudo da linguagem para a implantação de uma escrita revolucionária a inscrever o que seria o mais próprio do feminino no tocante a seu corpo, com a pretensão de abalar o sistema simbólico formatado pelo patriarcado, que não admitiria representações inéditas da mulher. É neste contexto que surge o Movimento da escrita feminina - que defendia um tipo transgressor de escrita, não prevista pela ordem falocrática da linguagem, cuja mecânica, se transposta para o social, promoveria transformações.

Na empreitada de questionar a lógica da identidade e da diferença, esta ala feminista se volta também a Foucault e Derrida. Do primeiro provém a desestabilização da unidade a-histórica atribuída ao corpo; do último, a noção de "falogocentrismo" e a estratégia da desconstrução. Com a psicanálise, a relação é conflituosa: se por um lado celebra a premissa do inconsciente como instância que abala a coerência do sujeito da filosofia e evidencia a interpelação da linguagem na constituição do sujeito sexuado, por outro, denuncia o que julgava serem os pilares patriarcalistas que firmariam seu arsenal teórico neste quesito as ideias de Derrida são acionadas.

Logocentrismo é o termo que aponta para a tendência presente no pensamento ocidental de privilegiar o logos, fundamentando-se na metafísica da presença em busca da verdade (Derrida, 1967/2006). O logocentrismo se sustenta na lógica da identidade, da exclusão e da polarização binária da diferença, tal como se dá a ver nos pares de opostos corpo/ mente, natureza/ cultura e homem/ mulher, o que acaba decretando valor e criando uma relação hierárquica entre seus elementos. "Desconstrução" contempla os procedimentos que visam interrogar o logocentrismo subjacente às obras literárias a se estender às publicações de Freud e Lacan.

O neologismo "falogocentrismo" nasce da junção deste logocentrismo com o termo "falo", que a psicanálise tomaria como o operador central da sexualidade - como se trata de um ingrediente em larga escala tomado pelo feminismo como masculino, conceder primazia a ele levaria ao apagamento da mulher. "Desconstrução" é associado a diversos nomes, como différance, "suplemento" e "mulher", e é aqui tomada como um lócus de excesso nos textos falogocêntricos, funcionando como um ponto no qual o texto se volta contra si próprio, problematizando a binaridade do mecanismo que traça a diferença (Grosz, 1989). A assimilação da noção de différance frustra consistências identitárias, sendo fundamental para o projeto de uma escrita não orientada por um registro organizado por binários substancializados e excludentes, tal como o que assegura o patriarcado.

Passemos às feministas francesas. Nossa intenção não é tecer uma leitura crítica de suas teorias, mas apresentá-las, para depois discorrermos sobre a postura lacaniana neste momento de efervescência cultural.

Luce Irigaray (1932-), filósofa, linguista e psicanalista, participa ativamente, em 24 de março de 1965, do debate fechado intitulado "A propósito da comunicação de Serge Leclaire: sobre o nome próprio", a constar no Seminário 12 de Lacan. Irigaray também se faz presente no Seminário 14, na lição de 1 de fevereiro de 1966, em discussão com Jakobson e o próprio Lacan. Ela levanta questões sobre a diferença entre sujeito do enunciado, sujeito da enunciação e shifter, mas o tom colaborativo e cordial entre Irigaray e Lacan se encerra anos depois. A publicação de seu primeiro livro, Speculum: de l'autre femme, em 1974, resultou em sua expulsão da École Freudienne de Paris, fundada por Lacan, e a impediu de dar continuidade ao ensino universitário que empreendia em Vincennes (Donovan, 2003). De toda forma, seu trabalho teve o devido reconhecimento dentro e fora da França - é imensa a influência que exerceu sobre Butler e Braidotti, por exemplo. Preciado (2002) chega a homenageá-la ao denominar os corpos transmutados pela tecnologia, estandarte de seu manifesto contrassexual, de "wittigs" (p. 36).

Irigaray defende que questionar a espoliação da mulher põe em xeque não só questões econômicas, sociais e morais, mas, sobretudo, o modo como o sistema patriarcal enquadra a linguagem.

Ao atribuir à mulher a inveja do pênis, segundo Irigaray (1974/1985), Freud não estaria pautado numa heterogeneidade, mas num tipo de negatividade. No 
complexo de castração, a criança vê a ausência de pênis da mulher, um não-órgão, não "outro" órgão - por que a distinção anatômica dos sexos parte necessariamente do pênis? Isso configura, segundo a autora, uma relação hierárquica entre homem e mulher pela anatomia. Não haveria em Freud uma discussão a respeito de algo tributário da especificidade da mulhernão existe um estágio da vulva, por exemplo - e da particularidade do seu prazer. No final das contas, é como se só houvesse um sexo.

Isto também se verificaria quando Freud atribui à mulher um superego fraco, menor senso de justiça, menos interesses sociais e menor capacidade sublimatória. É como se ela fosse fruto de um desenvolvimento insuficiente ou deformado quando comparada, sob os mesmos critérios e o mesmo percurso edípico, ao que se dá com o homem. E, pior, na saída do Édipo, ela só teria tais alternativas: neurótica, masculinizada, masoquista ou feminina - mas esse "feminina", mesmo assim, seria uma construção fálica.

Para ter inteligibilidade discursiva, cabe a ela a maternidade e a construção da mascarada. Contudo, a composição deste "parecer-mulher", no fundo, se edificaria a partir dos valores que os homens reconheceriam como importantes para ele, seria um processo fálico que, paradoxalmente, velaria a feminilidade. Da mesma forma, fazer-se de mãe, tomar o filho como substituto do pênis ausente também é um recurso fálico.

Irigaray (1974/1985) ainda insiste que os desenvolvimentos freudianos referentes à diferença sexual não deveriam ser sondados como atemporais, mas enquanto resultado do caldo histórico e cultural em que estava embebido, uma cultura "hommo-sexual" dirigida por uma disciplina patriarcalista de base vitoriana. Freud não teria se dado conta de que havia a tendência, em sua época, de tomar a anatomia como critério de verdade científica; ele não teria reconhecido se tratar somente de um discurso dentre outros a prevalecer em determinado tempo histórico. A autora acusa Freud de não questionar os fatores culturais que exigiam que a mulher abafasse sua libido no seu caminho rumo à feminilidade segundo a versão do homem - daí clamar que o movimento feminista exacerba a diferença.

Em Lacan, o principal alvo de Irigaray (1977/1985) é o registro simbólico. Para ela, Lacan - mesmo tendo ao seu dispor instrumentos científicos mais refinados, como a linguística estrutural de Saussure-padeceria do mesmo erro de Freud ao adotar o modelo de um sexo, mas munindo-se dos recursos simbólicos da linguagem. Lacan teria mantido a mulher presa a uma versão negativa do Édipo e às garras do falo, agora alçado ao status de significante.

Essa formulação de uma dialética das relações, sexualizadas pela função fálica, de forma alguma contradiz a manutenção do complexo de castração da menina de Freud (ou seja, sua falta ou não-ter falo) e sua subsequente entrada no complexo de
Édipo - ou seu desejo de obter o falo de quem é suposto o ter, o pai. Dessa forma, a importância da "inveja do pênis" da mulher não é posta em questão, mas é elaborada mais profundamente em sua dimensão estrutural. (Irigaray, 1977/1985, p. 62)

Outro argumento em prol de uma suposta orientação patriarcal inerente ao lacanismo seria percebido tanto no peso concedido quanto na própria nomenclatura de conceitos nucleares: nome do pai, lei do pai, metáfora paterna.

Nesse contexto, o pai é transcendental, imutável, idêntico a si e se reflete em todas organizações - nesse prisma, segundo Irigaray (1974/1985, 308), ele está fora das recolocações da história, ao passo que é tomado como fundamento da lei e prescreve um ideal de gozo -, estratégia retórica que tencionaria criar um cenário inabalável para perpetuar o poder nas mãos dos homens.

Tomando como referência o Seminário 20, Irigaray (1977/1985) problematiza a caracterização lacaniana do gozo feminino como inefável, suplementar à gerência fálica ou além da linguagem - ela interpreta tais descrições como uma sentença de exclusão do discurso. A mulher é não toda; todo é o homem. Por que associar o todo, já de largada, a ele? Como nada pode ser declarado sobre o seu gozo, mais uma vez a mulher se mantém como alguém que não tem nada a pronunciar sobre o que seria o mais próprio de si. Ela é associada à falta e ao objeto, ou seja, a termos que nossa cultura tende a ver como pejorativos.

"Não há A mulher ", como afirma Lacan (2010, p. 150), cabendo a elas serem tomadas "uma a uma". Irigaray vê nesse aforismo uma manobra política: tratálas uma a uma tem como finalidade oculta impedir que as mulheres, em conjunto, possam conquistar uma representação discursiva ontológica, o que ameaçaria o império masculino. Se a mulher não existe, ela parece só entrar na relação sexual como mãe. "Se há um discurso que demonstra isso, é o discurso analítico, por pôr em jogo, aqui, que a mulher só pode ser tomada como quoad matrem" (Irigaray, 1977/1985, p. 102).

Além de propor que se reajuste a relação mãefilha - a mãe transmitindo às filhas uma representação diferente do que seja uma mãe -, Irigaray (1984/1993) questiona se a psicanálise poderia lançar mão de outros recursos teóricos que revogassem o ofuscamento da mulher ao reduzi-la ao espaço da mãe - daí propor que a diferença sexual seja tratada a partir da topologia do cross-cap ou da garrafa, de Klein. Todo esse esforço buscava fugir do binarismo, que, segundo a autora, participa da engrenagem simbólica masculina condizente com os princípios dos sólidos - imutabilidade e retidão, isto é, com o "Um" monolítico -, transportando-se aos estudos das propriedades dos fluidos e a uma topologia não planificada em duas superfícies acopláveis que, em tese, acolheria a multiplicidade e a imprevisibilidade. Daí elucubrar a "simbolização dos dois lábios". Seu caráter de abertura, movimento e continuidade destoa da 
relação opositiva entre um item e outro. Além disso, não estaríamos nos orientando pelo olhar, sentido preferencial da trama especular do homem, mas pelo toque: dois lábios, sempre se tocando, formando um círculo, permitiriam, por exemplo, a ideia de ser mulher $e$ mãe (Irigaray, 1984/1993, p. 167). Não existiria mestria nem relação binária supressiva aqui.

O grande projeto de Irigaray é efetuar uma mutação na ordem simbólica, ao expor seu viés patriarcal. A tática não é simplesmente forjar meios de incluir o feminino na linguagem, mas alterar seu funcionamento. Há de se examinar as operações gramaticais, leis sintáticas, configurações imaginárias, redes metafóricas; a mecânica da linguagem que fortalece certas representações em detrimento de outras, produz certos significados e impossibilita outros. Novas palavras devem ser inventadas e usos inéditos concebidos para as remanescentes. A estrutura sintática e morfológica da língua deve mudar. Participa desse esquema o processo de mimesis.

Trata-se de reaplicar às mulheres os estereótipos femininos, incitar a repetição das visões degradantes atribuídas a elas. A imitação infindável sustenta o ideal de uma suposta origem, mas algo sempre escapa e questiona justamente se há origem. No final das contas, só há cópias sem um ponto de partida. Tais repetições nunca são bem-sucedidas - a mulher nunca é aquilo que pode ser dito ou expresso daquela forma, ou é algo a mais. "Da especularização para o espelho côncavo, no qual as imagens refletidas do sujeito, suas articulações sejam embrenhadas de transformações paródicas" (Irigaray, 1974/1985, p. 144). Ou seja, a mimesis é a reiteração irônica de um atributo negativo destinado à mulher com a intenção de revelar que ela não pode ser reduzida a ele, até que tal correlação seja descartada. Com a indução da mimesis, algo não é absorvido, e Irigaray situa aqui o gozo feminino.

Por fim, Irigaray $(1977 / 1985)$ comenta a representação do gozo feminino a partir da estátua Extase de Santa Teresa, de Bernini, que ilustra a capa do Seminário 20, de Lacan (2010): “Em Roma, tão longe, uma estátua, feita por um homem? Feita para ser olhada? Para saber do gozo de Teresa, talvez seja melhor recorrer a seus escritos. Mas como lê-la quando se é homem?" (p. 91). Da leitura do gozo da mulher surge a proposta de um tipo de escrita que abarcaria a singularidade da experiência do corpo feminino, categoricamente anunciado por Hélène Cixous em 1975. Assim, nasce o Movimento da escrita feminina: escrita experimental que tem finalidade política.

É somente pela escrita, da e na direção da mulher, assumido desaviar o discurso que tem sido governado pelo falo, que as mulheres se confirmarão mulheres em outro espaço que o reservado a ela no e pelo simbólico, ou seja, um lugar outro que o silêncio. (Cixous, 1975/1981, p. 251)
Cixous (1937-) é filósofa, professora universitária, poeta, dramaturga e crítica literária. Sua escrita, um complexo de teoria e ficção, é dedicada à desmontagem de poderosas narrativas, mitos e lendas presentes na literatura ocidental, que acabam por balizar nosso imaginário. Le rire de la méduse (1975/1981), célebre trabalho em que debate com a psicanálise, tem um clima de convocação a que as mulheres invoquem seus corpos como forma de expressão. "Cixous recorre a Clarice Lispector para ilustrar a conexão entre escritura do feminino e transformação social" (Brennan, 1997, p. 32).

Em 1975, ao lado de Catherine Clément, Cixous publica outra obra de grande repercussão, La jeune née, propondo que seria por meio da escrita que a mulher se colocaria por si mesma dentro da história - seja pela identificação com a heroína ficcional, na proposta de Cixous, seja com a histérica e a feiticeira, para Clèment (Wright citado por Brennan, 1997, p. 199) - Dora, paciente histérica de Freud, teria assumido a representação da mulher que ousou ir contra todo o poder do homem encarnado no mestre de Viena: a pretensão de lhe imputar seu saber levou a jovem a abandoná-lo.

Cixous expande seu programa ao teatro, que serviria como uma forma de "espacializar" esse tipo de escrita revolucionária (Schiach citado por Brennan, 1997, p. 218). Assim, cria as peças Le nom d'Oedipe e Portrait de Dora. Por sinal, no Seminário 23, Lacan se refere a esta última:

Gostaria de apresentá-los, ou de evocar, para aqueles que já a conhecem, a alguém de quem gosto muito e que se chama Hélène Cixous. Ela já tinha feito, parece, uma notinha sobre Dora em um número esgotado de Littérature, em que eu mesmo lancei "Lituraterra", e depois fez uma peça, O retrato de Dora, que está sendo encenada no Petit Orsay. Achei que não está nada mal. Disse o que pensava a esse respeito àquela a quem chamo de Hélène desde quando a conheci, e lhe disse que falaria disso. (Lacan, 2007, pp. 101-12)

Intervir nos códigos linguísticos, providenciar novas palavras, derrubar regras gramaticais, "escrever e, assim, forjar para ela uma arma anti-logos" (Cixous, 1975/1981, p. 250). Ou seja, há de se ir contra qualquer proposta de fundamentação identitária.

Em plano teórico, esta ala feminista prega o retorno ao modo de funcionamento do período pré-edípico, quando a diferença sexual ainda não se implantou - um período ainda não submetido à lei e à formatação regulatória fálica que exige a perda do caráter subversivo e disruptivo da pulsão à medida que se dirige à sua finalidade genital. A ideia é levar essa vulcânica parcialidade pulsional à atuação.

"Simbólico" e "falo", elementos cruciais para psicanálise, foram elaborados, segundo a autora, sob 
o cânone masculino com fins de conservar o poder na mão dos homens.

Aqui encontramos o inevitável homem das pedras, sustentando-se ereto em seu antigo reino freudiano, na maneira em que, para recuperar a velha figura do ponto em que a linguística é conceitualizada como "revigorante", Lacan a preserva no santuário do phallus (ø), "protegido" da falta referente à castração. O "simbólico" deles existe, ele detém poder. (Cixous, 1975/1981, p. 255)

Agora, abertamente em confronto com a letra lacaniana, ela afrima:

Não li "A significação do falo"? E sobre a separação, e sobre aquela parte do eu que, para nascer, deve-se submeter a uma ablação - uma ablação, eles dizem, sempre a ser celebrada pelo seu desejo? ... O que é o desejo originado a partir de uma falta? Um desejo bem escasso. (Cixous, 1975/1981, p. 262)

Dada a interpretação de que a psicanálise relegaria um lugar menor à mulher, por fim, Cixous (1975/1981) aconselha: "Cuidado, minha amiga, ao significante que te remeteria a autoridade de um significado .... Quebre o ciclo: não permaneça dentro do encerramento psicanalítico. Dê uma olhada, depois rompa (p. 263). Tal fúria encontra seu contraponto em Michèle Montrelay (1994), que "mantém com Lacan uma verdadeira relação de amor cortês", de acordo com Roudinesco (p. 562).

Nesse contexto, essa "figura magnífica da grande aventura lacaniana" (Roudinesco, 1994, p. 562) introduz a ele "O arrebatamento de Lol V. Stein", de Marguerite Duras, para seu encantamento. No debate fechado de 23 de junho de 1965, a constar no Seminário 12, de Lacan (2006), Montrelay é convocada a discorrer longamente sobre a obra de Duras. Por sinal, o entusiasmo de Lacan é tamanho que o leva a redigir neste mesmo ano o texto "Homenagem a Marguerite Duras pelo arrebatamento de Lol V. Stein".

Em 1977, Montrelay publica L'ombre et le nom, que toma tal obra de Duras como estandarte do feminismo literário. Os personagens ganham destaque justamente por serem atormentados, viverem no ócio, horrorizados e capturados pelo nada - é com essa feminilidade remetida ao negativo imprevisível, explosivo e que leva ao êxtase mudo que os homens se defrontam.

No romance, ao presenciar a longa cena da dança de seu noivo com outra mulher, Lol permanece indiferente, presa em um arrebatamento que a despossui de seu corpo, trancafiando-a em uma fascinante experiência de gozo - este seria o lugar da sombra que Montrelay destaca no gozo feminino. Se, com Beauvoir, tratava-se de uma mulher que buscava se libertar, exigia direitos, questionava a ordem cultural; com Duras, o feminino se desvela numa idiossincrasia até então não descrita, ao flertar com o vazio - mas sem aludir ao patológico.

Montrelay (1977) se esforça para dar uma sustentação teórica rigorosa aos esquemas da escrita feminina, cujos pressupostos poderiam ser estendidos à clínica dos sujeitos femininos e ainda promover o acesso a um universo que o simbólico não atingiria. Montrelay questiona se a técnica psicanalítica não deveria levar em conta a particularidade do modus operandi da mulher, particularizando as modalidades da transferência e da interpretação. O que, para além dos enunciados, deve ser escutado na fala feminina que revelaria com mais concisão sua especificidade? O ritmo e a musicalidade resultantes da "condensação periódica da articulação significante" (Montrelay, 1977, p. 28), cuja materialidade resiste ao conhecimento e não é suscetível à interpretação clínica mais comum.

Estaríamos aqui em outra dimensão, não aquela do significante nem do significado: dimensão real. Transpõem-se essas "zonas de sombras", pontos cegos do simbólico, indo do campo de articulação ao "abismo do nonsense que se abre em todo discurso, o real do discurso" (Montrelay, 1977, p. 29).

Quanto à castração feminina, Montrelay (1977) afirma: "a mulher não é mutilada do pênis que jamais teve, mas privada das sensações da sexualidade primária. Ela a esquece, ou mesmo recalca a feminilidade, e tal esquecimento constitui a castração simbólica da mulher" (p. 74). A castração simbólica da mulher é correlata da privação de sua sexualidade primordial. Se uma parte é suscetível à representação, entra no discurso e pode ser recalcada, há outra faceta da sexualidade feminina não representável - sua experiência de gozo que extrapola a diagramação fálica. Assim, a escrita feminina não deveria ser acolhida como uma tática mais eficaz para acessar o inconsciente e clarear o que até então insistia em permanecer na obscuridade, mas dar vazão à vertente real do feminino.

Júlia Kristeva (1941-) é filóloga, psicanalista, crítica literária, romancista e professora emérita da Universidade Paris 7. Seu vasto trabalho, aliado ao pós-estruturalismo, percorre os campos da linguagem e da arte, tangenciados pela análise cultural e política, assim como estabelece uma interface entre semiótica e psicanálise.

Lacan (1976-1977), demonstra entusiasmo pela sua obra. Em 17 de maio de 1977, com a própria autora na plateia de seu seminário, ele diz: "Então, por ser de grande importância, eu vou anunciar a vocês o lançamento pela Seuil de um texto chamado Polylogue, que é de Julia Kristeva. Eu gosto muito desse texto". Lacan (19761977) chega a propor uma mixagem entre polylogue e seu neologismo "linguisteria": "polilinguisteria" (p. 73).

Um curioso incidente histórico entre Kristeva e Lacan é a viagem que fariam em grupo à China. Em 1974, ao lado de Roland Barthes, Jean Wahl e Marcelin Pleynet, os dois comporiam a delegação da revista Tel Quel, organizada por Philippe Sollers, para visitar o 
território chinês. Lacan estaria animado em explorar o inconsciente dos chineses, já que, segundo Kristeva, seria uma instância não estruturada como uma linguagem, mas como uma escrita. Contudo, Lacan declinou do convite (Calvet, 2012, pp. 247-248).

Ao contrário do que se passou com Irigaray e Cixous, o lacanismo não foi tratado por Kristeva como um inimigo a ser combatido em seu suposto ranço patriarcal e heterossexista - ela (Kristeva, 1974/1984) se aplicou a incorporar o funcionamento do período pré-edípico e do corpo pulsional na sua proposta de revolução na linguagem.

As práticas de significação, o conjunto sociopolítico e a constituição do sujeito falante são disposições que, na visão de Kristeva, andam juntos - textualidade e subjetividade são tratadas a partir dos termos "semiótico" e "simbólico".

O período semiótico, para Kristeva, é regido por relações imaginárias quando os corpos de mãe e filho ainda são indiferenciados; seu funcionamento se dá fora da baliza fálica; as pulsões são parciais, em estado de dispersão. O semiótico é um momento em que não se adquiriram as mínimas unidades linguísticas, prevalecendo sensações, movimentos e vocalizações energia regida pelo processo primário; não "normatizável". "O semiótico precede todas as unidades, estruturas de oposição binária e formas hierárquicas de organização" (Grosz, 1989, p. 43). Se o corpo ainda não é uma unidade, a distinção sujeito-objeto ainda não pôde ser feita com clareza; a diferença sexual não se implantou.

Essa tendência disruptiva do semiótico precisaria ser reprimida para que o sujeito se tornasse um ser falante e entrasse na cultura sob a égide do simbólico e das leis da linguagem. Contudo, a entrada no simbólico não elimina o semiótico. Seu regresso se evidencia nas obras literárias de vanguarda - daí Kristeva se voltar para textos que sinalizem a instabilidade do sujeito e apontem para a deformidade do sentido; nos trabalhos experimentais de Mallarmé, Artaud e Joyce, principalmente. Kristeva considera que a capacidade de choque dessas publicações teria efeitos políticos, fazendo brotar representações não assimiláveis à ordem social. Se Irigaray perseguia a diferença entre um sexo e outro, Kristeva vai atrás da diferença interna de cada sujeito. Neste sentido, seria uma forma de introduzir o gozo excessivo e sem limites do semiótico em âmbito social via produção de textos, para desintegrar quaisquer representações estáveis, inviabilizar enquadramentos identitários, como o decreto d'A mulher.

É nesse sentido que nós podemos entender as advertências contra a recente invasão da paranoia nos movimentos das mulheres, assim como a escandalosa sentença de Lacan "A mulher não existe”. De fato, ela não existe com a letra maiúscula A, possuidora de uma unidade mítica - um poder supremo, no qual se baseia o terror do poder e o terrorismo como o desejo de poder. (Kristeva, 1979/1986, p. 205)
No período pós-Maio de 68, os debates na França se inflamam no próprio interior do feminismo; ao lado da abundância das revistas literárias, diversas facções surgem, umas vibrantemente opostas às outras, em diversos pontos teóricos e a respeito das estratégias que deveriam ser acatadas como forma de instigar reformas sociais. Se o movimento da escrita feminina - acusado, por muitos, de essencialista em sua abordagem do feminino - ganha terreno, surge também em solo francês o "Movimento de liberação das mulheres", sustentado por Antoinette Fouque, Monique Wittig e Josiane Chanel, que rechaçava qualquer tática ontologizante da mulher. O grupo Psicanálise e Política, fundado e dirigido por Fouque, figura central da profusão dos ideais desse segmento do feminismo, conquista espaço, promove locais de discussão onde as mulheres poderiam falar e ser escutadas, tanto com relação à vida política quanto à sua sexualidade. Prega-se a reparação e a valorização da relação mãe-filha, uma sexualidade entre mulheres a ser explorada, algo além do falicismo para o feminino. Além das reivindicações de ordem social, esse grupo propõe "escrever, traduzir, interpretar a história da sexualidade das mulheres a partir de uma escrita marcada, ela própria, pelo selo da diferença sexual" (Roudinesco, 1994, p. 562). Nesta toada, em 1974, Antoniette Fouque e seu grupo criam as Éditions des Femmes. Lacan estava por perto.

Durante essa época, Lacan é apanhado pelo ardor feminino .... No plano teórico, Lacan não renuncia a nenhum ponto de sua teoria anterior [a esse período dos anos 1970]. Mas o tom de seu discurso é diferente. Ele entendeu a mensagem de Antoniette e, se não adota nenhuma de suas afirmações, mostra-se sensível à nova retórica da escrita feminina. (Roudinesco, 1994, p. 566)

Tal grupo mantinha uma relação ambígua com a psicanálise: se, por um lado, prezavam a reconquista lacaniana que se deu via instrumentos da linguagem, e muitas dessas feministas eram vinculadas a escolas, como psicanalistas ou "psicanalisandas"; por outro, contestavam a implicação no plano social de alguns de seus pilares conceituais que contribuiriam para o cenário de desfavorecimento da mulher, assim como o funcionamento das próprias instituições psicanalíticas e elementos da técnica em jogo na prática clínica, a serem problematizados por Wittig.

O nome de Monique Wittig (1935-2003) é associado ao que se convencionou chamar de feminismo radical e feminismo lésbico. Seu trabalho se dá tanto na forma da teoria política, como se apresenta na coletânea de textos The straight mind (1992), quanto na da literatura de L'opoponax (1964). Adepta do marxismo, é crítica ferrenha da psicanálise - da teoria ao funcionamento do enquadre clínico e das próprias instituições psicanalíticas: tanto o psicanalista 
quanto os "ensinantes" de escola são encarados como mestres a submeter os pacientes e discípulos a um saber hegemônico e a uma conduta "adequada".

Wittig considera que a luta das mulheres deve se sustentar em um ponto de vista diferente daquele inicial do movimento feminista: no caso, retirando a mulher de cena - não se deve falar mais em opressão da mulher ou de mulher como diferente. Wittig propõe que se vá estrategicamente da mulher à lésbica, já que não seria prevista pelos preceitos da heterossexualidade.

Para a autora, a diferença sexual só existe enquanto determinação social submetida à mesma dialética presente na luta de classes. O pensamento dominante determina que há duas categorias de sexos com diferenças biológicas a serem refletidas em âmbito sociológico, legitimando, por exemplo, a divisão do trabalho. Se a mulher ocupa um lugar de espoliação nesse contexto, para que haja mudança, a diferença sexual deve ser banida. Neste sentido, "é a opressão que cria o sexo, e não o contrário" (Wittig, 1992, p. 2).

O que deve ser posto em xeque é a edificação das categorias "homem" e "mulher", que só acontece dentro do sistema heterossexual. Para minar este sistema, entendido por Wittig como um regime político que se apoia na submissão das mulheres, aquelas categorias devem ser abolidas política, filosófica e simbolicamente. Assim como as categorias "gênero", "sexo" e "diferença sexual", por fazerem parte da straight mind, que não só estatuiu nosso espaço de conhecimento, como regulamentou nossas instituições e toda cultura ocidental. A proposta de Wittig é a de que o humano seja abordado para além de toda categoria que envolva o sexual, rejeitando a ciência, inclusive a psicanálise, que se fundamenta nele ao se voltar ao sujeito.

Podemos dize que para Wittig (1992), ao contrário de Beauvoir, não se nasce mulher e se deve fazer de tudo para que jamais se consinta em se tornar uma - tornar-se mulher se escora em mitos: ser a mulher de um homem, ser mãe ou outras qualidades combinadas ao feminino. A não correspondência a estes ideais causa sofrimento. Wittig recomenda dissociar "mulher" enquanto mito, formação imaginária, de "mulheres" enquanto classe o movimento feminista deveria levar cada mulher a ter a consciência de que os problemas que enfrenta são essencialmente problemas das mulheres enquanto classe.

Na nossa cultura, há uma intuição de invariância da realidade social, como se não fosse alterável a partir dos conflitos de classe. Para Wittig, o psiquismo padeceria da mesma alienação - a fixidez dos conceitos em psicanálise seria forjada por um artifício de poder com fins de apagar as condições históricas subjacentes, o que, consequentemente, perpetuaria a situação de coação como se fosse naturalmente infundida.

Então se fala em troca de mulheres, diferença entre os sexos, ordem simbólica, Inconsciente, Desejo, Gozo, Cultura, promovendo um significado absoluto a esses conceitos, quando na verdade são apenas categorias fundadas a partir da heterossexualidade, que produz a diferença entre os sexos como um dogma político e filosófico. (Wittig, 1992, pp. 27-28)

Neste sentido, quanto ao simbólico:

... eles objetam que há uma ordem simbólica, como se estivessem falando de uma dimensão que não tivesse nada a ver com dominação. Pobre de nós, a ordem simbólica participa da mesma realidade que a ordem política e econômica. Há um continuum entre suas realidades, um continuum no qual a abstração se impõe à materialidade e pode formatar o corpo assim como a mente daqueles que oprime. (Wittig, 1992, p. 58)

O simbólico, nessa perspectiva, precisa ter alguma relação com a realidade - se não fosse assim, não haveria como vislumbrar renovações sociais a partir dele. A negativização deste registro, assim como a mitificação e fixação dos conceitos, seria no fundo uma manobra política com a intenção de ofuscar as condições históricas subjacentes, levando o sujeito a crer que a circunstância de submissão é um dado natural inabalável, barrando levantes de transformação.

Neste ambiente de ebulição do feminismo francês e do bombardeio sofrido, Lacan não contra-ataca explicitamente em seus ditos e escritos. Mas aclara o lugar da psicanálise ao se consagrar à máxima paradigmática da não relação sexual.

Nos anos 70, ao formalizar a tese da inexistência da relação sexual, para desgosto da plateia feminista francesa que na época buscava as bases teóricas para sustentar não mais a igualdade, como em um primeiro momento do feminismo, mas a especificidade da mulher em relação ao homem, Lacan afirma que "A mulher não existe". (Fuentes, 2009, p. 22)

Os aforismos "Não há relação sexual" e "A mulher não existe" estão no cerne do desenvolvimento de sua teoria da sexuação, que teve início no Seminário 18 e a ser definitivamente apresentada em suas proposições lógicas na tábua do Seminário 20. A maneira que Lacan escolhe para tratar da diferença dos sexos passa por avanços ao contemplar o falo enquanto função dentro da lógica e as díspares modalidades de gozo.

Podemos pensar a diferença de forma atributiva: seja a partir da contraposição de dois elementos opostos, a fixar identidades heterogêneas presentes, por exemplo, nas asserções "homens são de Marte, mulheres, de Vênus" e "homens são ativos, mulheres, passivas"; seja a partir da gradação de um terceiro termo comum, tal como o calor, no relato de Laqueur (2001), quando prevalecia o modelo do isomorfismo corporal no Renascimento: 
homens têm mais calor, mulheres, menos. Com Lacan, nem um nem outro. Se temos agora um item comum a ambos, a função fálica, não se pode falar que homens são mais fálicos que mulheres, nem vice-versa. Se temos duas modalidades de gozo incomensuráveis, não podemos identificar homem com gozo fálico e mulher com Outro gozo - mulheres têm acesso ao gozo fálico e homens podem ter acesso ao Outro gozo. Como Lacan trata a diferença dos sexos, então?

De acordo com a filósofa Geneviève Fraisse (2010), Lacan resgata uma noção antiga da diferença dos sexos, que se dá a partir da ideia de relação. Assim, diferença dos sexos aponta para o "reconhecimento de um conflito inerente à relação entre os sexos, de um desacordo" (p. 107). Ou seja, a sexuação não é uma teoria essencialista que visa decretar o que homens e mulher são, mas como se relacionam com o falo e com o gozo - a divergência das maneiras acaba impossibilitando o estabelecimento de qualquer relação entre seus lados.

Lacan escreve suas fórmulas. Lado esquerdo: existe $\mathrm{X}$ que não se submete à função fálica; todo $\mathrm{X}$ se submete à função fálica. Aqui Lacan parcializa o princípio da não contradição e, nessa operação, o "ao-menos-um", a exceção, é o que permite fundar o conjunto ou o universal do homem.

Lado direito: não existe $X$ que não se submeta à função fálica - dupla negação que não produz uma afirmação porque, na parte inferior, há: não todo $\mathrm{X}$ se submete à função fálica. Lacan nega o quantificador todo, o que é uma subversão lógica. Crucial apontar que não todo não é sinônimo de "nenhum" - "nenhum" diz respeito ao universal negativo e deste lado direito não se tem universalidade: "A mulher não existe"; seu conjunto é aberto. Como não temos dois universais, não é possível estabelecer relação entre um lado e outro. Há um obstáculo e é isso que as fórmulas da sexuação se prestam a formalizar logicamente - o que faz com que os lados não se conectem.

Le Gaufey (2007) localiza outras disparidades. Temos então um só universal e dois registros de existência diferentes. Se a negação entre as proposições do lado esquerdo é foraclusiva, por isso constitutiva do universal, temos do outro lado um indecidível: não se consegue deduzir se a proposição é verdadeira ou falsa simplesmente porque o elemento pertence ao conjunto ou não - há de se verificar um a um.

Este indecidível abre o lado mulher para o campo do Outro gozo - suplementar, e não complementar ao gozo fálico. A seu respeito, em rara referência ao Mouvement de libération des femmes, Lacan (2010) diz:

Há um gozo - já que nos limitamos ao gozo, gozo do corpo - que é ... se posso me exprimir assim, porque afinal, por que não fazer disso um título de livro? ... seria para o próximo da coleção Galilée: "Para além do falo" [Au-delà du phallus], seria bonito, hem! E depois, isso daria outra consistência ao M.L.F! Um gozo para além do falo, hem? (p. 151)

Enfim, as tábuas da sexuação pressupõem um tipo de diferença que prescinde de predicados e enquadres identitários, ao passo que impede que se discorra sobre ela enquanto entidade ontologizada. $\mathrm{O}$ que a sexuação mostra é mais radical: nenhuma relação pode ser estabelecida. A relação sexual falha e falha de duas maneiras divergentes. Lacan se verte à escrita do impasse lógico, tendo as feministas como interlocutoras.

\title{
Lacan and French feminism: the story of a (non) relation
}

\begin{abstract}
This paper presents French feminist theories of the 1970s, especially regarding the use and interpretation they have made of Lacanian psychoanalysis, such as what we consider to have been the epistemological attitude that Lacan adopted at that moment. Substantially influenced by Derrida and poststructuralism, Irigaray and Cixous make their criticisms of the theoretical psychoanalytic arsenal that supposedly matched the patriarchal model, while conceiving a kind of subversive writing with political aspirations. Also for this purpose, Montrelay and Kristeva offer a consistent theoretical support to this movement. Wittig, marked by Marxism, interprets Lacanian concepts as determined by heterosexual mentality as a political regime. We think that Lacan, attentive to the feminist enthusiasm of this period, chooses to develop his theory of sexuation and dedicates itself to the formalization of the aphorism "There is no sexual relation".
\end{abstract}

Keywords: french feminism, lacanian psychoanalysis, difference between sexes, non relation.

\section{Lacan y el feminismo francés: la historia de una (no) relación}

Resumen: Este artículo pretende presentar las teorías emprendidas por las feministas francesas de los años 70, especialmente sobre el uso y la interpretación que hicieron del psicoanálisis lacaniano, así como lo que consideramos haber sido la postura epistemológica que Lacan adopta en ese entonces. Marcadas fuertemente por Derrida y el postestructuralismo, Irigaray y Cixous tejen sus críticas al arsenal teórico psicoanalítico supuestamente concordante con el modelo patriarcal, mientras que conciben un tipo de escritura subversiva con aspiraciones políticas. También en este propósito, Montrelay y Kristeva pretenden ofrecer una fundamentación teórica consistente en este movimiento. Wittig, marcada por el marxismo, considera los conceptos 
lacanianos determinados por la mentalidad heterosexual como régimen político. Sostenemos que Lacan, atento al entusiasmo feminista de ese período, opta por desarrollar su teoría de la sexuación y se dedica a la formalización del aforismo "No hay relación sexual".

Palabras clave: feminismo francés, psicoanálisis lacaniana, diferencia de los sexos, no relación.

\section{Lacan et le féminisme français : I'histoire d'un (non) rapport}

Résumé : Cet article vise à présenter les théories des féministes françaises des années 1970, notamment en ce qui concerne I'utilisation et l'interprétation de la psychanalyse lacanienne, ainsi que ce que nous considérons comme la position épistémologique adoptée par Lacan en ce moment. Fortement marquées par Derrida et le post-structuralisme, Irigaray et Cixous posent leurs critiques de l'arsenal théorique psychanalytique supposée correspondant au modèle patriarcal, tout en concevant une sorte d'écriture subversive avec des aspirations politiques. Aussi à cet effet, Montrelay et Kristeva ont l'intention d'offrir un soutien théorique cohérent à ce mouvement. Wittig, marqué par le marxisme, lit les concepts lacaniens tels que déterminés par la mentalité hétérosexuelle en tant que régime politique. Nous soutenons que Lacan, attentif à l'enthousiasme féministe de cette période, choisit de développer sa théorie de la sexuation et se consacre à la formalisation de l'aphorisme "Il n'y a pas de rapport sexuel".

Mots-clés : féminisme français, psychanalyse lacanienne, différence des sexes, non rapport

\section{Referências}

Brennan, T. (Org.). (1997). Para além do falo: uma crítica a Lacan do ponto de vista da mulher. Rio de Janeiro, RJ: Record.

Butler, J. (2003). Problemas de gênero: feminismo $e$ subversão da identidade. Rio de Janeiro, RJ: Civilização Brasileira. (Trabalho original publicado em 1990)

Butler, J. (2004). Undoing gender. Nova York: Routledge.

Calvet, L.-J. (2012). Lacan e a escrita Chinesa: um inconsciente estruturado como escrita? Alea: Estudos Neolatinos, 14(2), 245-259. doi: 10.1590/S1517106X2012000200007

Cixous, H. \& Clément, C. (1975). La jeune née. Paris: Union Générale d'Editions.

Cixous, H. (1981). The laugh of the Medusa. In E. Marks \& I. De Courtivron, New French feminisms: an anthology (pp. 245-264). New York: Schocken Books. (Trabalho original publicado em 1975)

Cossi, R. K. (2018). A diferença dos sexos: Lacan e o feminismo (Tese de doutorado). Universidade de São Paulo, São Paulo.

Derrida, J. (2006). Gramatologia. São Paulo, SP: Perspectiva. (Trabalho original publicado em 1967)

Donovan, S. K. (2003). Luce Irigaray (1932? -). Internet Encyclopedia of Philosophy. Recuperado de https:// www.iep.utm.edu/irigaray

Fraisse, G. (2010). À côté du genre: sexe et philosophie de l'égalité. Lormont: Le Bord de l'Eau.

Freud, S. (2010). Sobre a sexualidade feminina. In Obras completas (P. C. de Souza, trad., Vol. 18, pp. 202-223). São Paulo, SP: Companhia das letras. (Trabalho original publicado em 1931)
Fuentes, M. J. S. (2009). As mulheres e seus nomes: Lacan e o feminino (Tese de doutorado). Universidade de São Paulo, São Paulo.

Grosz, E. (1989). Sexual subversions: three french feminists. Crows Nest: Allen \& Unwin.

Horney, K. (1993). Feminine psychology. New York: Norton. (Trabalho original publicado em 1967)

Irigaray, L. (1985). Speculum of the other woman. Ithaca: Cornell University Press. (Trabalho original publicado em 1974)

Irigaray, L. (1985). The sex which is not one. Ithaca: Cornell University Press, 1985. (Trabalho original publicado em 1977)

Irigaray, L. (1993). An ethics of sexual difference. Ithaca: Cornell University Press, 1993. (Trabalho original publicado em 1984)

Kristeva, J. (1984). Revolution in poetic language. Nova York: Columbia Press Univesity, (Trabalho original publicado em 1974)

Kristeva, J. (1986). Women's time. In T. Moi (Ed.), The Kristeva reader (pp. 187-213). New York: Columbia University Press.

Lacan, J. (1966-1967). Le séminaire, livre 14: logique du fantasme. Recuperado de https://bit.ly/3dFIADE

Lacan, J. (1976-1977). Le séminaire, livre 24: l'insu que sait de l'une-bévue s'aile à mourre. Recuperado de https:// bit.ly/2XCYvwN

Lacan, J. (2006). O seminário, livro 12: problemas cruciais para a psicanálise, 1964-1965. Recife, PE: Centro de Estudos Freudianos do Recife.

Lacan, J.(2007). Oseminário, livro 23: osinthoma, 1975-1976. Rio de Janeiro, RJ: Zahar. 
Lacan, J. (2010). O seminário, livro 20: encore, 1972-1973. Rio de Janeiro, RJ: Escola da Letra Freudiana.

Lago, M. C. de S. (2010). A psicanálise nas ondas dos feminismos. Recuperado de https://bit.ly/2UbJhgg

Laqueur, T. W. (2001). Inventando o sexo: corpo e gênero dos gregos a Freud. Rio de Janeiro, RJ: Relume Dumará.

Le Gaufey, G. (2007). El notodo de Lacan: consistencia lógica, consecuencias clínicas. Buenos Aires: El Cuenco de Plata.

Montrelay, M. (1977). L'ombre et le nom: sur la feminité. Paris: Éditions de Minuit.

Preciado, B. (2002). Manifiesto contra-sexual: prácticas subversivas de identidad sexual. Madrid: Opera Prima.

Roth, M. (2000). Freud: conflito e cultura: ensaios sobre sua vida, obra e legado. Rio de Janeiro, RJ: Zahar.
Roudinesco, E. (1994). História da psicanálise na França. Rio de Janeiro, RJ: Zahar.

Rubin, G. (1975). The traffic in women: notes on the “political economy” of sex. In R. R. Reiter (Ed.), Toward an anthropology of women (pp. 157-210). New York: Monthly Review Press. Recuperado de https://bit.ly/ $374 \mathrm{HVc} 6$

Wittig, M. (1992). The straight mind and other essays. Boston: Beacon Press.
Submissão: 15/03/2018

Revisão: 11/06/2019

Aprovação: 01/06/2020 